\title{
People first
}

Shaun Sellars continues this exciting and essential series on ethical dilemmas in dentistry which appears in every second issue of the $B D J$.

Sometimes it seems that we're constantly bombarded with images of perfect dentistry, invisible composites and bright white veneers. It's easy to lose focus on what dentistry actually is for a large section of the population.

Recently I met a patient who was recovering from Guillain-Barré syndrome. She was making good progress from her initial diagnosis some months ago but was still confined to a wheelchair and had no real use of her limbs. Her brain, however, was as sharp as ever and we spent the best part of half an hour talking about her condition and how much better she was now in comparison to a few months ago.

Her main complaint was that in the three months since she had been moved to a care home, none of the carers had brushed her teeth properly. She was the only resident who didn't have Alzheimer's disease, and although the carers were good at making residents comfortable and presentable, their teeth were largely an afterthought.
I have another patient who is an Oral Health Champion for their particular centre. She is fully engaged with the importance of looking after the teeth of her residents, but she struggles to find supplies and information to enable her to pass on what she's learned to other carers. Many residential homes are desperate for dentists with the time and appropriate training to come in and help them in their care. While the provision of dental care in a community setting is excellent in neighbouring counties, it is virtually non-existent in the rural area I live and work in. Community services appear to be the long forgotten ugly-stepchild of the dental profession, when in reality they often care for the people that most of us can't or don't want to treat.

Our patients are getting older. If their dentistry isn't failing already, it will do in the future. Everything we do fails. The ravages of dementia and arthritis, among many other issues, make it difficult for these patients to look after their teeth themselves. Along with this, the community services are stretched

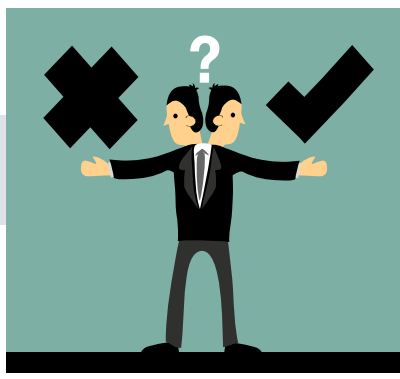

beyond reason. Those with the most need often have the most difficultly obtaining the care that they deserve.

We already have great resources to help these patients, but for whatever reason, they're not getting out to all the people that need them. Either that, or the carers in question don't realise the importance of the guidance. As a profession we have a duty to care for the whole population, not just those who want the ideal, perfect straight teeth. We should also be aware of our place in the larger healthcare picture. We need to reach out individually and collectively to those areas of care where the importance of the basics of what we do isn't understood.

As for the lady with Guillain-Barré syndrome... I brushed her teeth. And it was the most rewarding thing I'd done for months.

Dentistry is healthcare. We treat people not teeth. And we put people first.

\section{BDA launch a lifeline for profession under stress}

The British Dental Association (BDA) has launched a new partnership with the award-winning employee assistance programme Health Assured to provide all BDA members with a 24-7 comprehensive and confidential counselling service.

The service offers expert advice and compassionate guidance, a pathway to structured telephone counselling for members or their dependants and face-to-face counselling sessions, alongside advice on any issues that cause anxiety or distress including debt management, accountancy, lawsuits, consumer disputes, property or neighbour disputes.

The BDA has committed itself to tackling the epidemic of mental health issues facing the profession. Its own research has found that almost half of dentists say stress in their job is exceeding their ability to cope. BDA surveys have found high levels of stress and burnout among the profession, with a fifth of respondents (17.6\%) admitting they had seriously thought about committing suicide.

The Health Assured coverage includes access to their Health e-Hub App (via the App Store and Google Play) which offers access to holistic health and wellbeing support anywhere and anytime, an online portal with a virtual library of wellbeing information, and a range of online $\mathrm{c}$ behavioural therapy (CBT) self-help modules, factsheets and invaluable advice videos from leading qualified counsellors.

BDA members can log into their My BDA account for the member-only access details.

BDA Chair Mick Armstrong said: 'Mental health matters. Evidence shows dentists are now in desperate need of support, and sadly all too often aren't even offered signposts to basic services. We set out to guarantee that none of our members need to suffer in silence. Whatever is causing stress, with our friends at Health Assured we can now offer counselling, advice and tools, 24 hours a day, 365 days a year.'

https://www.bda.org/healthassured 